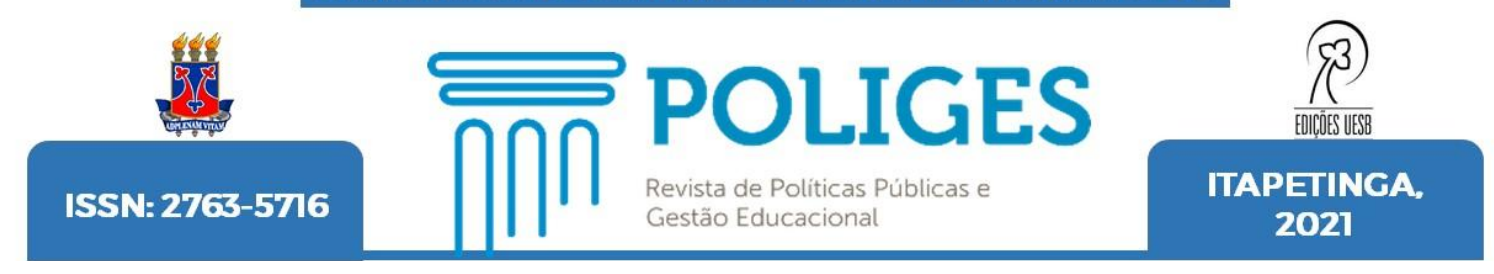

\title{
CONTEXTUALIZAÇÃO HISTÓRICA E HISTÓRIA EDUCACIONAL DE BOM JESUS-PI
}

\author{
HISTORICAL BACKGROUND AND EDUCATIONAL HISTORY OF BOM JESUS-PI
}

\begin{abstract}
CONTEXTUALIZACIÓN HISTÓRICA E HISTORIA EDUCATIVA DEL BOM JESUS$\mathrm{PI}$
\end{abstract}

\begin{abstract}
Maria Aparecida Alves da Costa
ORCID Id: https://orcid.org/0000-0001-5213-4869 Mestrado em Educação - Universidade Estadual do Ceará - Brasil

Francinalda Machado Stascxak

ORCID Id: https://orcid.org/0000-0001-6152-4295 Mestrado em Educação - Universidade Estadual do Ceará - Brasil

Francisca Genifer Andrade de Sousa

ORCID Id: https://orcid.org/0000-0001-8280-3250

Mestrado em Educação - Universidade Estadual do Ceará - Brasil
\end{abstract}

DOI: $10.22481 /$ poliges.v2i1.8519

Resumo: $O$ estudo trata da história local e educativa de Bom Jesus, cidade nordestina do interior piauiense. O objetivo foi compreender, a partir da contextualização histórica, a história da educação de Bom Jesus, mediante pesquisa qualitativa do tipo histórica. Os resultados inferem que essa região, em seus primórdios, teve a sua história e constituição educativa estritamente ligada à atividade de grupos religiosos, que ali chegaram e, ao construir uma capela, instigaram o desenvolvimento populacional e educativo. Especificamente no que toca o campo educacional, averiguou-se que, em face do descompromisso público com essa matéria, os religiosos foram os responsáveis por iniciar a escolarização formal, tendo firmado parceria, em alguns momentos, com o governo estadual, sendo a década de 1970 a mais exitosa, pois foi marcada pela fundação das primeiras escolas de variados níveis. Conclui-se que a reconstituição histórica educacional de Bom Jesus, além de ensejar maior conhecimento sobre o processo de expansão da escola, permite desvelar aspectos macrossociais dessa cidade e, por conseguinte, do Piauí e do Nordeste brasileiro.

Palavras-chave: Bom Jesus-PI. Educação formal. História da Educação

Abstract: The study deals with the local and educational history of Bom Jesus, a northeastern city in the interior of Piaui. The aim was to understand, from the historical contextualization, the history of education in Bom Jesus, through qualitative research of the historical type. The results infer that this region, in its early days, had its history and educational constitution strictly linked to the activity of religious groups, who arrived there 
and, by building a chapel, instigated population and educational development.Specifically with regard to the educational field, it was found that, in view of the public disengagement with this matter, the religious was responsible for initiating the formal schooling, having signed a partnership, at times, with the state government, with the 1970s being the most successful, as it was marked by the foundation of the first schools of varying levels. It is concluded that the historical educational reconstitution of Bom Jesus, besides increasing knowledge about the school expansion process, it allows to see in macrosocial aspects of this city and, consequently, of Piauí and the Brazilian Northeast.

Keywords: Bom Jesus-PI. Formal education History of education

Resumen:El estudio trata sobre la historia local y educativa de Bom Jesus, una ciudad del noreste del interior de Piauí. El objetivo fue comprender, desde el contexto histórico, la historia de la educación de Bom Jesus, a través de una investigación cualitativa de tipo histórico. Los resultados infieren que esta región, en sus inicios, tuvo su historia y constitución educativa estrictamente ligada a la actividad de los grupos religiosos, quienes llegaron allí y, mediante la construcción de una capilla, instigaron el desarrollo poblacional y educativo. Específicamente en el ámbito educativo, se constató que, ante la falta de compromiso público con este tema, los religiosos eran los encargados de iniciar la escolarización formal, habiendo establecido una alianza, en ocasiones, con el gobierno estatal, siendo el La década de 1970 fue la más exitosa, ya que estuvo marcada por la fundación de las primeras escuelas de distintos niveles. Se concluye que la reconstrucción histórica educativa de Bom Jesus, además de brindar un mayor conocimiento sobre el proceso de expansión de la escuela, permite develar aspectos macrosociales de esta ciudad $y$, en consecuencia, de Piauí y el Nordeste de Brasil.

Palabras clave: Bom Jesus-PI. Educación formal. Historia de la Educación

\section{Introdução}

Minha terra tem o encanto

Que a natureza Ihe deu E até o seu nome é santo, Bom Jesus é o nome seu.

É pura fertilidade O solo que tem por cá, $\mathrm{Na}$ lavoura tem fartura, Se plantando tudo dá.

Sua água é cristalina, Riqueza que tem aqui, É a melhor do planeta, No sul do meu Piauí.

Esta terra abençoada, É a terra de Santa Cruz, É a minha terra querida, Minha linda Bom Jesus. (Aurélio Rosal, p. 109-110) 
É com esse poema de Rosal (2007), escritor, filho de Bom Jesus, que iniciaremos este ensaio. Analisando o seu conteúdo, em linhas gerais, podemos notar que a percepção do autor é a mais bela possível sobre sua terra. Terra esta que possui um encanto inestimável e que de natureza fértil, ajuda a população a tirar o seu sustento. A poesia valoriza as características naturais do lugar, em especial, ressalta a água cristalina e o solo fértil, características muito fortes desse lugar. No entanto, Bom Jesus é um município do Nordeste brasileiro situado ao sul do Piauí que enfrenta muitos problemas de ordem econômica e política, como tantos outros lugares do interior do Brasil.

Bom Jesus teve as suas terras demarcadas no início do século XIX a partir da expulsão de povos indígenas no sul do Piauí e com a chegada de colonos oriundos de outros estados da região Nordeste, como destaca Raposo (2004, p. 21), ao asseverar que "os índios Gueguê e Tapuias tinham sido expulsos de suas terras do Sul do Piauí; colonos pernambucanos, paraibanos, cearenses e baianos chegaram procurando pastagens fartas para seus rebanhos e aqui encontraram ubérrimas para a lavoura".

Bom Jesus situa-se ao extremo sul do Piauí, a cerca de $630 \mathrm{~km}$ de distância da capital piauiense, Teresina. Localiza-se às margens do Rio Gurguéia, fazendo parte da mesorregião do Sudoeste Piauiense, assim como da Microrregião do Alto Médio Gurguéia. No cenário atual, possui aproximadamente 24.960 habitantes (IBGE, 2018). Em sua origem, foi batizado por Buritizinho, pois no local concentrava-se um vasto campo da palmeira chamada buriti, espécie de planta predominante da Mata dos Cocais que faz parte da Sub-região Meio-Norte, englobando assim dois estados: o Piauí e o Maranhão.

Seguindo a mesma trilha de outras regiões do país, e não somente do Nordeste, Piauí foi um estado que teve o seu desenvolvimento educativo e populacional estritamente ligado à atuação de grupos religiosos que professavam a fé católica e visavam à disseminação do cristianismo. Nessa empreitada, também ofertavam serviço educacional em um cenário de completa negligência por parte do poder público às populações mais afastadas dos centros urbanos (SOARES; VIANA, 2016). Desse modo, questiona-se: como foi efetivado o processo de desenvolvimento histórico educacional de Bom Jesus-PI? 
Ante tal indagação, o objetivo do presente escrito é compreender, a partir da contextualização histórica, a história da educação de Bom Jesus-PI, o que aponta, por conseguinte, para a reconstituição da história desse lugarejo. A relevância do estudo consiste em lançar luz sobre aspectos históricos de uma pequena cidade brasileira, possivelmente, em situação de anonimato, considerando que até o momento são poucos os pesquisadores que se debruçaram sobre a sua história, principalmente quando se trata da história da educação.

Nesse viés, a pesquisa é de abordagem qualitativa, já que vem realçar minúcias não apreendidas em estudos macrossociais situados no universo das operacionalizações variáveis (MINAYO, 2013); é do tipo histórica, pois reconstitui aspectos da história local de Bom Jesus, o que viabiliza o entendimento da sua origem e organização estrutural ao longo do tempo, tocando em aspectos relacionados aos âmbitos social, cultural, econômico, político e, principalmente, educativo, foco deste estudo. Para concretizar tal feito, fez-se uso de documentos, prioritariamente bibliográficos, que tratam sobre a educação e história de Bom Jesus.

Além da presente introdução, que contextualiza a temática, expõe o questionamento, o objetivo, a relevância, bem como esclarecer os aspectos metodológicos, o texto foi organizado em outras três seções, com vistas a melhor compreensão leitora. A primeira, intitulada "Origens de Bom Jesus", trata sobre a história desse lugarejo interiorano nordestino desde a sua gênese, no século XIX, avultando discussões concernentes à atuação do grupo de religiosos que ali chegou e foi essencial para o seu desenvolvimento, e destacando as suas principais características locais. Em seguida, "O processo educacional de Bom Jesus" vem discutir, buscando detalhar em minúcias, como procedeu o desenvolvimento educativo dessa região, tocando em aspectos como condições e financiamento escolar. Por último, as "Considerações finais" retomam o objetivo aqui proposto a fim de respondê-lo, destaca os principais resultados alcançados e aponta perspectivas de estudos futuros. 


\section{Origens de Bom Jesus - PI}

Assim como na maioria dos municípios piauienses, a presença da igreja católica foi muito forte na constituição de Bom Jesus. Um grupo de romeiros em meados do início do século XIX ergueu uma capela para adorar Bom Jesus da Boa Sentença e, em volta deste edifício, foram-se estabelecendo algumas famílias, proporcionando assim, um crescente desenvolvimento da povoação no local, conforme o relato seguinte:

A família de Nicolau Barreiros, ou Barrente, chegou às margens do rio Gurgueia e ficou aproveitando os férteis baixões e instalou sua moradia de "pau-a-pique", coberta de sapé, perto do riacho que corria manso e limpo até o Gurgueia. Esta família trazia no coração muito amor a Jesus e a Jesus do perdão, Bom Jesus da Boa Sentença. "Seu" Nicolau logo ergueu uma capelinha de pau-a-pique e sapé com frente para o riacho, onde era celebrada todos os anos a novena e o festejo ao santo (RAPOSO, 2004, p. 21).

Portanto, Nicolau foi uma personalidade importante nos primórdios de Bom Jesus, pois foi a partir da sua chegada e da construção de uma capela, que iniciou a construção do município de Bom Jesus. Em 1838, a partir da Lei Provincial $n^{\circ} 101$, de 22 de setembro, criou-se o distrito de Bom Jesus do Gurgueia. Mais adiante, em 1855, criou-se então, o atual município de Bom Jesus, resultado do desmembramento de território do município de Parnaguá pela Resolução provincial n 397 de dezembro de 1855, ocorrendo a instalação apenas em 25 de março de 1858 (SETUVAL, 1999).

Nesse período, o Brasil ainda encontrava-se como Colônia de Portugal, e as leis provinciais da época eram regidas pelo Conselho Geral de Província da Constituição de 1824, constituição esta, outorgada por D. Pedro I, em 25 de março de 1824. Com o passar do tempo, mais precisamente em 1938, período no qual o Brasil já não era mais uma colônia e, sim, uma república, o território que era chamado de Bom Jesus da Boa Sentença, com a divisão territorial de outras províncias, recebeu a designação de Bom Jesus. O trecho a seguir traz detalhes desse processo: 
Nos quadros de divisão territorial datados de 31-XII-1936 e 31-xii-1937, bem como no anexo do Decreto Lei estadual $n^{\circ} 52$ de 29 de março de 1938, o município em apreço, já sob designação de Bom Jesus, simplesmente, se apresenta constituído, como anteriormente, por um distrito apenas, - de igual nome. [...] Dá-se o mesmo nas divisões territoriais do Estado, fixadas pelos Decretos-leis estaduais n. ${ }^{\circ} 147$, de 15 de dezembro de 1938 e 754, de 30 de dezembro de 1943, para vigorarem, respectivamente, nos quadriênios 1938-1943 e 1944-1949 (SETUVAL, 1999, p. 07 e 08).

Entendemos, portanto, que em 1938, Bom Jesus tornou-se território independente, porém foi emancipado politicamente apenas em 1948, sendo seu primeiro prefeito o Sr. Francisco da Cruz Filho (Dr. Cruz) e o Vice-prefeito, João Nepomuceno da Fonseca, com mandato de 21/04/1948 a 31/01/1951 (SETUVAL, 1999). A respeito dessa época, podemos destacar aqui uma síntese real de como era Bom Jesus na época de sua emancipação política, que segundo Parente Apud RAPOSO (2004, p. 14).

\begin{abstract}
Nasci aos trinta dias do mês de março de 1947, num pequeno povoado à margem do Rio Gurguéia, no extremo sul do estado do Piauí. O meu Bom Jesus era então sertão bravio, inteiramente desprovido dos recursos que vivificam o homem civilizado. Lá não existia luz elétrica, telégrafo, água canalizada, escolas, ou seja, nada existia em matéria de conforto e progresso, nem mesmo uma bola para jogar pelada de futebol. Vivíamos todos, ricos e pobres, das dádivas generosas da natureza. A população da vila não passava de 600 habitantes. A vila não era outra coisa senão uma praça em forma retangular, no centro da qual localizava-se o mercado ou feira, sendo que nos lados do retângulo, medindo aproximadamente 400 metros, ficavam as ruas com as casas dos coronéis fazendeiros, e nos fundos dessas ruas situavam-se as casas de colonos ou seus protegidos.
\end{abstract}

A riqueza de detalhes descrita pelo autor nesse relato autobiográfico que se imbrica com o contexto local, leva-nos a visualizar a pequena cidade de Bom Jesus em plena década de 1940, sendo esta "abandonada" pelo poder público por não ser emancipada. A partir de sua emancipação, a esperança de que bons tempos viriam, trazendo consigo o desenvolvimento social, econômico e educacional que permeava o imaginário do seu povo.

Em entrevista realizada por Costa (2019, p. 48) com o historiador Aurélio Rosal, de 77 anos, foi possível compreender detalhes de como eram supridas as 
necessidades básicas de Bom Jesus como, por exemplo, sobre a energia elétrica e a água encanada. Vejamos o relato:

Aqui em Bom Jesus quando eu era pequeno tinha uns 6 anos, a energia elétrica era à lenha, tocada por uma caldeira pra produzir essa energia, aí quando era 15 minutos antes das 11 da noite ele dava um sinal, ele dava três sinais, apitava a cidade toda escutava, era pequena e era indicando que ia apagar a luz da cidade (ROSAL, 2018).

A respeito das condições do acesso à água, ele continua o seu relato e destaca que

\begin{abstract}
O povo ia pegar no centro, os que moravam pra cá era no rio, os que moravam daqui pra lá era um grotão que tinha aí que secou, hoje não tem mais água, mas era caudaloso, tinha muita água, tinha poço que as mulheres tomavam banho, tinha um lugar chamado poço dos homens ali naquela rua da prefeitura descendo, tinha era poço que a gente mergulhava. Os poços em cima de uns lajeiros, tudo de lajes, água, água cristalina, aí tinha uns olho d'água mais pra cima que minava água na pedra e o povo apanhava água ali, todo cidadão tinha jumento, tinha ancoreta que botava no jumento ia pegar água nesse olho d'água pra abastecer a casa (ROSAL, 2018).
\end{abstract}

Esses dois trechos permitem-nos voltar no tempo e imaginar a precariedade de um lugar que, por mais que fosse pequeno, ainda assim, a necessidade do povo era extrema. E essa não era só uma dificuldade da cidade de Bom Jesus, mas de todo o sul do Piauí e do Nordeste brasileiro. Com o passar do tempo, a situação foi melhorando e, a partir da década de 1960, chega a Bom Jesus uma comunidade católica denominada "Ordem Mercedária"1 que tinha a missão não só de evangelizar, mas também de proporcionar uma vida social mais digna para os bonjesuenses. Iniciou-se, assim, um movimento de luta por direitos e por melhores condições de vida, incluindo nesse aspecto, a causa educativa, assunto que será tratado logo adiante.

\footnotetext{
${ }^{1}$ Ordem religiosa de origem espanhola, que chegou a Bom Jesus no ano de 1956, com o Bispo Dom José Vásquez Díaz. Essa ordem religiosa chegou a Bom Jesus em sua segunda vinda ao Brasil, pois a primeira vez aconteceu em 1639 na província do Maranhão. Disponível em: http://mercedarios.com.br/historico. Acesso em: 17 de março de 2021.
} 


\section{O processo educacional de Bom Jesus}

Bom Jesus, em plena década de 1940, era um município pequeno com poucas casas e poucas ruas, mas servia de referência para os demais municípios da região, uma vez que os outros municípios ao seu redor eram ainda menos "evoluídos". Era um município pouco desenvolvido e, devido a isso, existia apenas um estabelecimento educativo, a Escola Franklin Dória, fundada em 1930, que atendia apenas o antigo Primário, que funcionava da $1^{a}$ à $4^{a}$ série. Essa instituição foi a "primeira escola gratuita, então chamada "Escola Singular Franklin Dória", depois Escola Agrupada "Franklin Dória" e atualmente Unidade Escolar Franklin Dória" (SETUVAL, 1999 p. 10, grifos do autor).

Como destacamos no tópico anterior, Bom Jesus inicia um processo de desenvolvimento mais aligeirado com a chegada de um bispo na prelazia de Bom Jesus, chamado Dom José Vásquez Díaz, bispo vindo da Espanha para o Brasil, trazido pela Ordem Mercedária. À época, a Igreja Católica não exercia sobre a sociedade somente seu poder religioso, mas atuava também nos âmbitos social e educacional.

Nesse rumo, o desenvolvimento de Bom Jesus deve-se muito ao domínio da Igreja Católica, desde o seu fortalecimento com a chegada de romeiros movidos pela fé católica, que foram construindo suas casas às margens do Rio Gurguéia. Dom José Vásquez Díaz, de acordo com Raposo (2004, p. 73) chegou a Bom Jesus,

[...] em março de 1957, como bispo auxiliar e suplicou a Dom Inocêncio que lhe deixasse ficar em Bom Jesus, sede da Prelazia. Dom José sempre acreditou no potencial deste lugar tão temido pelos missionários. [...] Este bispo tem no seu brasão como lema "Viriliter age", que quer dizer "Trabalha varonilmente" - e foi o que ele fez durante sua vida. Ao chegar, a primeira coisa que fez foi visitar toda a parte a ele encomendada.

É notória a pertinente atuação deste bispo na cidade de Bom Jesus, pois suas obras sociais estão preservadas até hoje como é o por exemplo da construção de uma vila denominada "Vila das Mercês", a construção de parte da "BR 135", que é a rodovia que liga Bom Jesus a outras cidades, assim como a construção de outros prédios, como o Seminário Maior e até a Escola Normal. O bispo, hoje é 
homenageado em Bom Jesus com a denominada Universidade Estadual de Bom Jesus (UESPI), denominado "Campus Dom José Vásquez Díaz", no auditório "Dom José" assim como a Avenida Dom José Vásquez Díaz (RAPOSO, 2004).

Com a existência de apenas uma escola primária, sendo esta a única escola de Bom Jesus, surgia a necessidade de a população continuar sua vida educacional, contudo, não havia o acesso necessário aos níveis mais elevados de educação. Foi nesse momento que a ordem religiosa entrou em um acordo com o poder político para que fundassem um Ginásio a fim de atender a séries maiores, o secundário, e assim pudesse suprir as necessidades educacionais da região. No ano de 1958, um político chamado Odilon Parente, doou para a prelazia do município um espaço grande já construído para que funcionasse a instituição (CRISPIM, 2018).

A partir dessa doação, o Bispo da época, Dom José Vásquez Díaz juntamente com outros religiosos, fundaram em 1958 um ginásio, que recebeu o nome de "Ginásio Odilon Parente", em homenagem ao político. Este iniciou seu funcionamento apenas no turno da manhã e somente algum tempo depois, também no turno da tarde, já que o turno matutino não conseguia atender à demanda de alunos matriculados, pois como já foi citado, o Ginásio atendia também a população do restante da região. Segundo entrevista de Costa (2019) Dionéia Crispim, ex-diretora da instituição, era uma escola de cunho particular, porém tratava-se de um valor simbólico, quantia que era utilizada exclusivamente para pagar o salário dos professores.

Além da aquisição do Ginásio Odilon Parente, a prelazia de Bom Jesus, em nome do bispo Dom José Vásquez Díaz adquiriu várias "escolas-comércio", visto que estávamos passando pelo período da ditadura militar (1964-1985) e que o ensino técnico no país estava em abrangência. Sobre esse aspecto que representou significativas mudanças no contexto educacional de todo o país, Saviani (2013, p. 381) aponta que:

A partir do pressuposto da neutralidade científica e inspirada nos princípios de racionalidade, eficiência e produtividade, a pedagogia tecnicista advogou a reordenação do processo educativo de maneira a torná-lo objetivo e operacional. De modo semelhante ao que ocorreu no trabalho fabril, pretendeu-se a objetivação do trabalho pedagógico. 
Ou seja, o ensino técnico consistia na qualificação da mão de obra para a atuação no mercado de trabalho, uma vez que a iniciativa do governo era apenas de desenvolver métodos que acelerassem a economia do país e a educação, de fato, era abordada apenas de modo tangencial. Em Bom Jesus, de acordo com Novo (2017, p. 24), “em 1967 foram construídas oficinas, uma metalúrgica e uma sapataria destinadas ao aprendizado dos futuros profissionais de Bom Jesus e região", como representa a Imagem 1.

Imagem 1 - Dom José Vásquez Díaz e dois mestres de obras em frente ao prédio das oficinas (metalúrgica e sapataria)

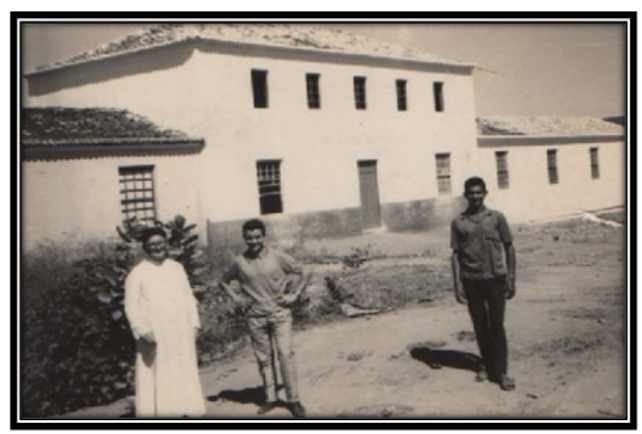

Fonte: Arquivo da diocese de Bom Jesus-PI

Na imagem acima, observando no ângulo da esquerda para a direita, temos o bispo Dom José Vásquez Díaz, acompanhado de dois mestres de obras os quais não foram identificados, no ano de 1967 , no ato de entrega do prédio que pode ser visualizado atrás do bispo juntamente com seus companheiros, que fora destinado para as atividades práticas das oficinas (metalúrgica e sapataria). A construção desse prédio, teve como organização mantenedora, as Obras Sociais do Gurguéia (OSG), organização esta que fazia parte da Prelazia de Bom Jesus. A aquisição dessas oficinas trouxe, para o município e região, melhorias nas condições de vida das pessoas, uma vez que elas teriam uma profissão a seguir, melhorando também a economia do município (NOVO, 2017). A agricultura, no entanto, continuava sendo praticamente a única fonte de renda e de trabalho na região.

Com o acesso ao ensino secundário, que correspondia da $5^{a}$ à $8^{a}$ série, a educação bonjesuense sentia a necessidade de dar continuidade ao aspecto educacional, visto que já existia o ensino primário e o secundário. Somente em 1970 a prelazia de Bom Jesus, por meio da unidade mantenedora Obras sociais do 
Gurguéia e mediante a resolução do Conselho Estadual de Educação (CEE) de $n^{\circ}$ 4/70 deu início ao funcionamento da Escola Normal Helvídio Nunes de Barros, única Escola Normal da região no ano de 1970.

Ainda na década de 1970, com o crescimento da população local por meio do desenvolvimento do município, foi criada em 1972 a segunda escola primária de Bom Jesus, a Escola Araci Lustosa, como podemos analisar nas palavras de Sousa e Andrade (2013, p. 1679):

Esta instituição iniciou suas atividades de ensino em 12 de maio de 1972, durante o Governo de Alberto Tavares Silva. A escola recebeu este nome em homenagem a senhora Araci Maria Ferreira Lustosa, sendo a primeira professora diplomada no curso magistério da cidade de Bom Jesus (PI).

Com a finalidade de atender à demanda educacional de Bom Jesus e regiões circunvizinhas, a Unidade Escolar Araci Lustosa foi de importância considerável para o desenvolvimento do sul do Piauí. Já em 1979, extinguiu-se o Ginásio Odilon Parente, uma vez que a escola era de cunho particular, surgindo assim, um novo ginásio, dessa vez estadual, o Ginásio Joaquim Parente, que se destacou por sua qualidade no ensino e por ter a regalia de ser público, beneficiando, sobremaneira, os alunos que não tinham condições necessárias para financiar seus estudos.

Inicialmente, em 1979, a escola funcionava dois turnos, manhã e tarde, de $5^{a}$ a $8^{a}$ série (atual $6^{\circ}$ ao $9^{\circ}$ ano). Devido a inauguração dessa nova escola os alunos tiveram mais oportunidades para estudar e não teriam a necessidade de irem para outras cidades ou mesmo pagarem uma escola particular mesmo sem terem recursos suficientes (SOUSA; SOUSA; ANDRADE, 2016, p. 7).

Como podemos notar, Bom Jesus estava crescendo e a educação estava conseguindo universalizar-se para atender à demanda dos alunos, pois estes já não precisavam mais se deslocar para cidades maiores ou capitais de outros estados para continuar sua vida educacional. Importa salientar que as escolas estavam comportando o número de alunos, pelo fato de essas instituições não serem acessíveis a todas as crianças, pois muitas ajudavam em trabalhos domésticos, 
assim como nas lavouras, uma vez que o acesso à escola era impossibilitado e negligenciado por muitos (JINZENJI; GALVÃO; SILVA, 2012).

Como já citado anteriormente, a economia de Bom Jesus era baseada nos setores agrícola e pecuário. Logo, a população necessitava de qualificação profissional, pois a educação que tínhamos na década de 1980 pautava-se no modelo tecnicista. O ensino técnico tinha como objetivo principal, segundo o Decreto-lei $n^{\circ}$ 9.613, de 20 de agosto de 1946, em seu Artigo $3^{\circ}$, única lei que regulamentava o ensino agrícola na época:

1. Formar profissionais aptos às diferentes modalidades de trabalhos agrícolas.

2. Dar a trabalhadores agrícolas jovens e adultos não diplomados uma qualificação profissional que lhes aumente a eficiência e produtividade.

3. Aperfeiçoar os conhecimentos e capacidades técnicas de trabalhadores agrícolas diplomados.

No ano de 1981 foi implantado o Colégio Agrícola de Bom Jesus, que fazia parte da Universidade Federal do Piauí, embora na cidade não houvesse ainda um campus universitário. Na escola, funcionava o ensino primário, secundário e médio com o ensino técnico em agropecuária. Maria Luíza, em entrevista concedida à Costa (2019), relata que o prédio do Colégio Agrícola era de posse do município, uma vez que foi construído no mandato de 1967 a 1971, pelo seu irmão Renato Parente, prefeito na época: "quando criou (construiu) o Colégio Agrícola ele era do município, aquele colégio foi construído por meu irmão na época da gestão dele, do Renato Parente. [...] aí entrou um prefeito e deu a escola para o estado (ELVAS, 2018).

Sobre esse fato, Setuval (1999) comenta que um dos fatos marcantes do mandato do prefeito Adelmar Benvindo, entre os anos de 1977 a 1983, foi a doação de um terreno de 30 hectares para a Fundação Universidade Federal do Piauí (FUFPI), para o funcionamento do Colégio Agrícola de Bom Jesus, no dia 17 de outubro de 1981 (SETUVAL, 1999). Destarte, podemos considerar que Bom Jesus precisava de uma escola com essa modalidade, uma vez que a economia do município era fundamentalmente baseada no setor agropecuário, no entanto, essa preparação serviria de suporte para os trabalhadores do campo. 
A respeito da precariedade que seguia constante em Bom Jesus em virtude da falta de investimento público do estado, a cidade continuou desenvolvendo-se e, em 1988, Bom Jesus já contava com duas escolas primárias, a Unidade Escolar Franklin Dória e a Unidade Escolar Araci Lustosa; um Ginásio que atendia o ensino secundário chamado Joaquim Parente; um Colégio Agrícola que funcionavam os ensinos Primário, Secundário e o Ensino Médio com o Técnico em Agropecuária; e uma escola destinada à formação de professores, a Escola Normal Helvídio Nunes de Barros.

Essa quantidade de instituições educativas, ainda que não fosse suficiente para abarcar a todos os interessados, já que (pelo menos algumas delas) possuía seleções para ali estudar, permite concluir que Bom Jesus era uma cidade em constante expansão em termos educacionais, fator que estava diretamente relacionado com a possibilidade de melhores condições de vida daquela população.

\section{Considerações finais}

Objetivou-se compreender, a partir da contextualização histórica, a história da educação de Bom Jesus-PI, o que permitiu reconstituir, também, a história dessa região desde a sua origem, já que a história educacional é imbricada ao desenvolvimento dessa região. Trata-se de um estudo de abordagem qualitativa, do tipo histórica, desenvolvida mediante pesquisa bibliográfica variada atinente à temática em realce.

Certifica-se que a cidade de Bom Jesus, seguindo a trilha de outras regiões do Piauí e do Nordeste brasileiro, tratava-se de um local que sofria pela falta de atenção dos gestores públicos, que não investiam em serviços básicos, como saúde e educação. A sua população, que no século XIX começava a se constituir em torno de uma capela alicerçada para adorar Bom Jesus da Boa Sentença, apenas no século seguinte, após forte desenvolvimento populacional e atuação de religiosos, começou a contar com a possibilidade de mudar a condição econômica a partir da escolarização.

Apurou-se que a oferta de escolarização formal em Bom Jesus teve início com um grupo de religiosos que, em 1958, fundou o Ginásio batizado por Odilon Parente e, ao mesmo tempo, implantaram-se escolas-comércio, empreendimentos 
importantes no contexto ditatorial que o Brasil vivenciava à época, no qual a formação para o mercado de trabalho era apontada como necessidade imediata. Apesar dos interesses econômicos, esse feito viabilizou à população bonjesuense ascender socialmente, já que ora contavam com instrução profissional que permitiria adentrar no mercado de trabalho, melhorando as condições de vida familiar e do município, que teve a sua economia alavancada.

A década de 70 apresentou-se como palco de marcos valiosos para a história da educação de Bom Jesus, na medida em que no ano de 1970 a única escola normal da região deu início às suas atividades, corroborando para a formação da classe docente; em 1972, foi fundada a segunda escola primária da região; e em 1979, finalmente, o governo estadual criou o Ginásio de caráter público, destinado àqueles que não possuíam condições econômicas para financiar os seus estudos. No início da década seguinte, em 1981, foi a vez da implantação do colégio agrícola e, nessa perspectiva, chegamos a 1988 com duas escolas primárias, um Ginásio, um colégio Agrícola e uma Escola Normal. Essa expansão significava que os bonjesuenses não necessitariam mais recorrer a outras cidades em busca de escolarização, o que garantiria mais conforto e, possivelmente, diminuiria a evasão escolar.

A reconstituição histórica de Bom Jesus, especificamente no que concerne ao desenvolvimento educativo, permite evidenciar aspectos comuns a outras regiões mais afastadas dos centros urbanos brasileiro, onde a negligência do poder público era ainda mais forte e refletia diretamente nas condições de vida da população. $O$ processo de expansão da escola, no entanto, nem sempre seguiu o mesmo ritmo daquele trilhado por Bom Jesus e, por isso mesmo, é interessante apontar para a necessidade de realização de outros estudos, com foco na história educativa de outras regiões, o que permitirá compreender com maior profundidade como se constituiu a democratização (ainda não concretizada) do acesso à educação no Brasil.

\section{Referências}

BRASIL. Decreto-Lei n 9.613, de 20 de agosto de 1946. Institui a Lei Orgânica do Ensino Agrícola: Rio de Janeiro, RJ, 1946. 
COSTA, Maria Aparecida Alves da. Maria Cinobelina Elvas: Docência na Escola Normal (1981-1988). 2019. 130 f. Dissertação (Mestrado Acadêmico) - Universidade Estadual do Ceará, Fortaleza, 2019. Disponível em:

http://siduece.uece.br/siduece/trabalhoAcademicoPublico.jsf?id=95576. Acesso em: 17 de março de 2021.

JINZENJI, Mônica Y.; GALVÃO, Ana. Maria; SILVA, Simone. A. Memórias sobre a infância no meio rural: a escola e os outros espaços de sociabilidade. Revista Portuguesa de Educação, 2012, v. 25, n. 2, pp. 9-33 2012. Disponível em: https://revistas.rcaap.pt/rpe/article/view/3000. Acesso em: 17 mar. 2021.

IBGE - Instituto Brasileiro de Geografia e Estatística. Educação de Bom Jesus. 2018. Disponível em: https://cidades.ibge.gov.br/brasil/pi/bom-jesus/panorama. Acesso em: 22 jun. 2019.

MINAYO, Maria Cecília de Souza (Org.); DESLANDES, Suely Ferreira; GOMES, Romeu. Pesquisa social: teoria, método e criatividade. 33 ed. Petrópolis, RJ: Vozes, 2013. Benigno Nunes Novo

NOVO, Benigno Nuñes. A biografia de Dom José Vasquéz Diaz. Amazón 2017. PIAUÍ. Resolução n. CEE/04/70, de 27 de fevereiro de 1970. Teresina: Conselho Estadual de Educação do Piauí, 1970.

RAPOSO, Fernando Cascón. História da Paróquia de Bom Jesus da Boa Sentença. 142 p. Ilustradas. Bom Jesus, 2004.

ROSAL, Aurélio Coelho. Fogo da Terra. Bom Jesus. 2007.

SAVIANI, Dermeval. História das ideias pedagógicas no Brasil. Campinas, SP: Autores associados, 2013.

SETUVAL, Carlos Alberto Rodrigues. Evolução Política do Município de Bom Jesus-PI. Bom Jesus: Câmara Municipal de Bom Jesus. 1999.

SOARES, Carla Poennia Gadelha; VIANA, Tania Vicente. Jovita Alves Feitosa: memórias que contam a história da educação nas prisões cearenses. Educação \& 
Formação, v. 1, n. 1 jan/abr, p. 140-158, 4 jan. 2016. Disponível em:

https://revistas.uece.br/index.php/redufor/article/view/96. Acesso em: 17 mar. 2021.

SOUSA, Raiane Pereira. ANDRADE, Maria Aparecida Fernandes de Sousa. Escola

Araci Lustosa (Bom Jesus-PI): Um olhar sobre sua história In: XII Encontro

Cearense de História da Educação e II Encontro Nacional do Núcleo História e

Memória da Educação. Anais... Fortaleza. UFC, 2013.

SOUSA, Raiane Pereira de; SOUSA, Wagner. Alves de; ANDRADE, Maria

Aparecida Fernandes de Sousa; Revisitação Histórica das Instituições Escolares de

Bom Jesus-PI na década de 70. In: III CENEDU-Congresso Nacional de Educação.

Anais... Natal, 2016.

SOBRE AS AUTORAS

\section{Maria Aparecida Alves da Costa}

Doutoranda e Mestra em Educação pelo Programa de Pós-Graduação em Educação da Universidade Estadual do Ceará (PPGE-UECE). Membro do grupo de pesquisa Práticas Educativas, Memórias e Oralidades (PEMO). Bolsista da Coordenação de Aperfeiçoamento de Pessoal de Nível Superior (CAPES). E-mail: mariapedagoga99@gmail.com

\section{Francinalda Machado Stascxak}

Mestranda em Educação pelo Programa de Pós-Graduação em Educação (PPGE-UECE). Membro do grupo de pesquisa Práticas Educativas, Memórias e Oralidades (PEMO). Bolsista da Coordenação de Aperfeiçoamento de Pessoal de Nível Superior (CAPES). E-mail: naldastascxak@gmail.com

\section{Francisca Genifer Andrade de Sousa}

Doutoranda e Mestra em Educação pelo Programa de Pós-Graduação em Educação da Universidade Estadual do Ceará (PPGE/UECE); graduada em Pedagogia pela mesma instituição. Bolsista da Coordenação de Aperfeiçoamento de Pessoal de Nível Superior (CAPES). E-mail: geniferandrade@yahoo.com.br 